\title{
Sequential aiming movements and the one-target advantage in individuals
} with Down syndrome

Lawrence, G.P.; Reilly, N.E.; Mottram, T.M.; Khan, M.A.; Elliott, D.

\section{Research in Developmental Disabilities}

DOI:

10.1016/j.ridd.2013.08.006

Published: 08/09/2013

Peer reviewed version

Cyswllt i'r cyhoeddiad / Link to publication

Dyfyniad o'r fersiwn a gyhoeddwyd / Citation for published version (APA):

Lawrence, G. P., Reilly, N. E., Mottram, T. M., Khan, M. A., \& Elliott, D. (2013). Sequential aiming movements and the one-target advantage in individuals with Down syndrome. Research in Developmental Disabilities, 34(11), 3858-3866. https://doi.org/10.1016/j.ridd.2013.08.006

\section{Hawliau Cyffredinol / General rights}

Copyright and moral rights for the publications made accessible in the public portal are retained by the authors and/or other copyright owners and it is a condition of accessing publications that users recognise and abide by the legal requirements associated with these rights.

- Users may download and print one copy of any publication from the public portal for the purpose of private study or research.

- You may not further distribute the material or use it for any profit-making activity or commercial gain

- You may freely distribute the URL identifying the publication in the public portal ?

Take down policy

If you believe that this document breaches copyright please contact us providing details, and we will remove access to the work immediately and investigate your claim. 
This article was accepted in its current form for publication in Research in Developmental Disabilities on 20.08.2013

Running Head: MOVEMENT INTEGRATION IN PERSONS WITH DOWN SYNDROME

Sequential aiming movements and the one-target advantage in individuals with Down syndrome

Gavin P. Lawrence ${ }^{\mathrm{a}}$

Niamh E. Reilly ${ }^{\mathrm{a}}$

Thomas M. Mottram ${ }^{\mathrm{a}}$

Michael A. Khan ${ }^{\mathrm{b}}$

Digby Elliott ${ }^{\mathrm{c}}$

a. School of Sport, Health, and Exercise Sciences, Perceptual Motor Group,

Bangor University, LL572PX.

b. Department of Kinesiology, Faculty of Human Kinetics, University of Windsor, ON N9B $3 \mathrm{P} 4$.

c. School of Sport and Exercise Sciences, Liverpool John Moores University, L3 3AF

Correspondence address: $\quad$ Dr Gavin Lawrence

School of Sport, Health, and Exercise Sciences

Institute for the Psychology of Elite Performance

Bangor University

George Building

Holyhead Rd

Bangor

Gwynedd

LL57 2PX

Email: g.p.lawrence@bangor.ac.uk

Tel: $\quad+44(0) 1248388283$

Fax: $\quad+44(0) 1248371053$

Keywords: Down syndrome; one-target advantage; target directed movement; multiple limbs;

movement integration 
MOVEMENT INTEGRATION IN PERSONS WITH DOWN SYNDROME

\begin{abstract}
Research has revealed that individuals with Down syndrome (DS) have elevated reaction times, longer movement times, and greater movement errors during single-target single-limb actions compared to their typically developing (TD) peers. These perceptualmotor impairments have been attributed to both central processes and the physical phenotype associated with DS. The purpose of the present study was to directly investigate these possible central and peripheral deficits by examining how individuals with DS plan and execute more complex movements. Three groups (DS, TD, and individuals with an undifferentiated intellectual disability; UID) of 8 participants completed a single target movement, a two-target movement performed by a single arm, and a two-target movement where the first movement was performed with one arm and the second movement performed with the other arm. For all groups and all conditions, movement times revealed a one-target advantage (OTA). Specifically, times to the first target were longer in the two-target responses compared to the single-target response. In general, the OTA finding reveals that persons with DS utilise planning strategies similar to their TD peers when performing sequential actions involving two targets and two arms. Furthermore, because the OTA was observed in both the single- and two-arm two-target responses the interference in movement one associated with having to make a subsequent movement is not due to peripheral processes associated with single limb constraints. Rather, individuals with DS treat movements within a sequence as functionally dependent. Thus, the central processes associated with the timing of the implementation of the second element of the movement appear to be responsible for the interference that leads to the OTA.
\end{abstract}


MOVEMENT INTEGRATION IN PERSONS WITH DOWN SYNDROME

\section{Introduction}

Down syndrome (DS) is a genetic condition involving chromosomal abnormality; specifically an additional $21^{\text {st }}$ chromosome (full or partial) occurs in every cell of the body. This genotype results in individuals with DS demonstrating different physiological, anatomical, and neurological features to those of the typically developing (TD) population. Researchers have highlighted differences between the DS and TD populations in the form of longer movement onset and reaction times (Arisi, et al., 2012; Davis, Sparrow, \& Ward, 1991; Henderson, Illingworth, \& Allen, 1991; Masumoto, Abe, \& Inui, 2012), longer movement times, and greater movement errors for DS compared to TD (Elliott, Welsh, Lyons, Hansen, \& Wu, 2006; Hodges, Cunningham, Lyons, Kerr, \& Elliot, 1995). These perceptual-motor impairments have been attributed to both central processes (i.e., Frith \& Frith, 1974) and peripheral anatomical characteristics (Henderson et al., 1991; Morris, Vaughan, \& Vaccaro, 1982).

In simple goal-directed movement, the perceived slowness of individuals with DS when performing simple aiming or tapping tasks has been attributed to an inability to develop central control of upper limb movements (Frith \& Frith, 1974). This issue with motor programming is thought to cause over dependence on response-produced visual and kinesthetic feedback for the online regulation of movement (Simon, Elliott, \& Anson, 2003). Anson (1992) suggested that the slower reaction and movement times observed in individuals with DS indicate the involvement of deficits in both peripheral and central mechanisms. Central processing deficits in DS relate to complications that occur in the time before the required stimulus of the movement. These central processing issues occur when the participant initiates the cognitive process of movement preparation. Whereas, peripheral processing deficits in DS are said to occur during the events of muscle activation up until the time at which onset of movement occurs (Simon et al., 2003). It has been proposed that 


\section{MOVEMENT INTEGRATION IN PERSONS WITH DOWN SYNDROME}

central deficits in the motor control of individuals with DS occur due to neurophysiology deficits that affect the retrieval or initiation of motor programs and lengthen both reaction time and movement time (Carvalho \& Vasconcelos, 2011; Kerr \& Blais, 1987). On the other hand, peripheral anatomical deficits relate to issues with inertia of limb mechanics and muscle organisation. These limb inertia and muscle organisation issues may be due to the prevalence of hypotonia in individuals with DS (Anson, 1989; Anwar \& Hermelin, 1979; Henderson, Morris, \& Frith, 1981) and/or atypical patterns of muscle activation (Anson \& Mawston, 2000).

In target directed aiming, Hodges et al. (1995) reported that movement times were approximately twice as long for participants with DS compared to the TD population. Furthermore, the acceleration profiles of the DS participants contained significantly more discontinuities (indicative of online movement adjustment) than those of TD participants. Similarly, Almedia, Coros, and Hasan (2000) have reported that individuals with DS spend proportionally more time in target regions compared to TD individuals. In both Hodges et al. (1995) and Almedia et al. (2000) movement time differences between DS and TD were attributed to participants with DS making greater use of feedback-based corrections during movement execution. This strategy was reportedly adopted in order to reduce discrepancies between the position of the limb and target that emerged due to central deficiencies in movement planning and feed-forward processes.

The majority of past research on motor performance in children and adults with DS has been conducted using single target-directed movements. The purpose of the present study was to investigate how individuals with DS plan and execute the more complex responses involved in multiple target movements. Researchers have adopted numerous approaches to understanding how multiple segment movements are prepared and executed. Following from an extensive body of research that has investigated the relation between 


\section{MOVEMENT INTEGRATION IN PERSONS WITH DOWN SYNDROME}

reaction time (RT) and the number of response segments/elements (e.g., Henry \& Rogers, 1960; Klapp, Wyatt, \& Lingo, 1974; Sternberg, Monsell, Knoll, \& Wright, 1978; Vidal, Bonnet, \& Macar, 1991), researchers have recently directed their efforts towards examining the time it takes to execute movements (e.g., Adam et al., 2000; Helsen, Adam, Elliott, \& Buekers, 2001; Khan, Lawrence, Buckolz, \& Franks 2006). The typical finding has been that movement time to an initial target is slowed when subjects are required to make a subsequent movement (Adam et al., 2000; Chamberlin \& Magill, 1989; Helsen et al., 2001; Khan, Mottram, Adam, \& Buckolz, 2010; Khan, Sarteep, Mottram, Lawrence, \& Adam, 2011). This one-target advantage (OTA) suggests that individual elements in a response are not programmed or executed independently. Furthermore, research has shown the OTA to be a robust phenomenon since it occurs under both left and right hand responses (Helsen et al., 2001; Lavrysen et al., 2003), with and without vision (Lavrysen, Helsen, Elliott, \& Adam, 2002), and is resistant to practice (Lavrysen et al., 2003).

Several hypotheses have been proposed to explain the OTA. The movement integration hypothesis (MIH) (Adam et al., 2000) explains the OTA by combining the notion of advance planning and on-line control processes. Specifically, the hypothesis poses that all movement programming is completed before movement initiation and, in order to facilitate a smooth and efficient transition between segments, the implementation of the second segment is performed online, concurrent with the execution of the first movement. The increased cognitive control associated with the implementation of the second segment during the production of the first segment in two target responses leads to interference. This interference results in a lengthening of MT to the first target.

Other researchers have proposed movement constraint based explanations for the OTA (Sidaway, Sekiya, \& Fairweather, 1995). Because spatial variability increases as movement progresses (Schmidt, Zelaznik, Hawkins, Frank, \& Quinn, 1979; see Khan et al., 


\section{MOVEMENT INTEGRATION IN PERSONS WITH DOWN SYNDROME}

2006, for a review), the movement constraint hypothesis $(\mathrm{MCH})$ proposes that movements to the first target in two element responses must be performed in a more constrained manner in order to ensure the accuracy requirements of the subsequent movement are met. That is, constraining the accuracy of the first movement has the subsequent effect of providing a less variable starting position for the second movement. This strategy results in a reduced need to adjust the movement parameters of the second element leading to a more integrated and efficient overall response program.

Although the OTA had been extensively studied for aiming tasks in which movements were performed with a single arm, Khan et al. (2010) recently investigated whether the OTA would emerge when there was a transfer between arms in sequential aiming movements. They compared three movement conditions; a single target movement, a two-target movement performed by a single arm, and a two-target movement where the first movement was performed with one arm and the second movement performed with the other arm. The results of this study revealed the OTA in both the single and dual arm 2-target responses. As such, Khan and colleagues concluded that the processes underlying the OTA likely occur at a central level (i.e., the retrieval or initiation of motor programs). The rationale for why these processes must occur at the central rather than peripheral level is that if the interference occurred at the peripheral level (i.e., limb mechanics) then the OTA would not have been observed when there was a switch between the arms involved in production of the first and second movement sequences (i.e., the dual arm condition). This is because in the two-arm condition, the starting position of the second segment is fixed and does not depend on endpoint variability of the first movement.

Because there is debate about whether motor deficits in individuals with DS are primarily due to central processing impairments involved in the planning of motor responses (Frith \& Frith, 1974; Hodges et al., 1995; Inui, 2007; Lam, Hodges, Virji- Babul, \& Latash, 


\section{MOVEMENT INTEGRATION IN PERSONS WITH DOWN SYNDROME}

2009) and/or the peripheral issues related to anatomical and neural drive characteristics associated with DS (Henderson et al, 1991; Latash, 2007; Morris et al., 1982), the present investigation examined the root cause of these motor deficits in DS by adopting the experimental design of Khan et al. (2010). Specifically, we compared single-target movements with two-target sequences both when the two-target responses were performed with a single arm and when there was a switch between the arms used to execute the first and second movement segments. The presence of the OTA for individuals with DS would first reveal that, similar to the TD population, sequential aiming movements are not functionally independent and that the control processes underlying the production of the second segment influences the execution of the first segment. Secondly, by comparing movement times to the first target in the single and dual arm two-target conditions, inferences could be made regarding whether movement planning and control deficits associated with DS occurred at the central or peripheral level. For example, a significant OTA in the single-arm but not the twoarm two-target movements would point to interference at the peripheral but not the central level. This is because the two movements in a dual-arm condition are performed by separate effectors. Hence, the switch between arms during a response removes the possible interference and movement deficit effects associated with functional dependencies between muscles, effectors and their organisation. Further, an OTA of similar magnitude for both the single and dual arm conditions would support a central locus of interference. Finally, a significant but smaller OTA in the dual-arm compared to single-arm two-target responses would provide support for both central and peripheral interference suggesting the deficits in movement control of those with DS reside in a combination of both central and peripheral processes.

\section{Method}

\section{1. Participants}


MOVEMENT INTEGRATION IN PERSONS WITH DOWN SYNDROME

Twenty-four adult volunteer participants were recruited; 8 DS (3 males and 5 females; mean age $=24$ yrs, $S D=6.2$, range $=18-37), 8$ undifferentiated intellectual disability without DS (UID; 5 males and 3 females; mean age $=26$ yrs, $\mathrm{SD}=7.1$, range $=20-37$ ), and 8 TD $(4$ males and 4 females; mean age $=22$ yrs, $\mathrm{SD}=4.5 \mathrm{yrs}$, range $=18-30)$. To ensure parity between group chronological age, data were analysed using a one way ANOVA. Results revealed no significant difference $\left(F_{(2,21)}=1.05, p>.05\right)$. All participants completed the British Vocabulary Peabody scale (BVPS) as a measure of mental age and intellectual functioning (Dunn \& Dunn, 1997). Whilst the UID were classified as having an intellectual disability from local service departments and parent(s)/guardian(s), this disability was not syndrome specific (i.e., Down syndrome, Williams syndrome, Prader-Willi syndrome). A one way ANOVA conducted on the raw BVPS data revealed that the TD group (mean = $28.13, S D=3.59$ ) had significantly greater levels of intellectual functioning compared to the DS $($ mean $=19.00, S D=1.86)$ and UID $($ mean $=20.25, S D=2.44)$ groups $\left(F_{(2,21)}=26.29, p\right.$ $<.001$ ), whilst the DS and UID groups were not significantly different from one another.

Participants in the DS and UID groups were recruited from Mencap Cymru support groups across North Wales and participants in the TD group were recruited from the research institution's student body. Of the 16 participants with an intellectual disability all lived in either a group home or with a parent/caregiver and were involved in some form of physical activity (e.g., athletics, football, etc.) at least once a week. In addition, 4 (DS) and 3 (UID) were in full time education and 4 (DS) and 5 (UID) were involved in part time employment. All participants volunteered for the study, were naive to the experimental hypothesis, were right-hand dominant (handedness was determined via both self report and by observing which hand was used when writing; in all instances the self report and writing hand did not differ), and reported normal or corrected to normal vision. Consent forms were signed before the start of the experiment and all participants were assessed for Mental Capacity under the 


\section{MOVEMENT INTEGRATION IN PERSONS WITH DOWN SYNDROME}

guidelines for the Mental Capacity Act 2005 prior to consent. Specifically, Mental Capacity was assessed by the researcher under the guidance and supervision of professional and experienced practioners employed by Mencap Cymru. Here participants were provided with information (both verbally and visually) about the experiment and then asked a series of questions related to this information. Responses were graded for understanding by the researcher who was under the supervision of experienced Mencap Cymru practioners and had been trained in Mental Capacity assessment through Mencap Cymru. The testing was conducted in line with the procedures for consent to psychological research by people with an intellectual disability (see Arscott, Dagnan, \& Kroese, 1998). The study was carried out according to the ethical guidelines laid down by the institutions Ethics Committee for research involving human participants.

\section{2. Apparatus}

Participants were seated in front of a horizontal table top upon which was situated a wooded frame with six microswitches mounted under square keys (25mm x 25mm). The keys were positioned in three sets of pairs along the participants' midline (see Figure 1). The horizontal distance between each key in a pair was $35 \mathrm{~mm}$ (centre to centre) whilst the longitudinal distance between each key pair was $150 \mathrm{~mm}$ (centre to centre) resulting in an Index of Difficulty of 3.6 bits (Fitts, 1954). Participants were positioned so that each key could be easily reached and pressed with their index finger. The start positions were the most distal keys, the middle keys were designated as Target 1 , and the most proximal keys as Target 2 .

Insert Figure 1 about here

\section{3. Task and Procedure}


MOVEMENT INTEGRATION IN PERSONS WITH DOWN SYNDROME

At the start of each trial, the right index finger was placed on the start position (right key) while the left index finger was placed on target 1 (left key). Participants performed three aiming tasks. In the one target (1T) task, participants moved their right index finger from the start position to target 1 (see Figure 1a). The other hand remained stationary on target 1 . In the two target, single limb (2T1L) task, participants moved their right index finger from the start position to target 1 and then to target 2, pressing both targets with the same index finger (see Figure $1 b$ ). The other hand remained stationary on target 1 . In the two target, two limb (2T2L) task, participants moved their right index finger from the start position to target 1 and then moved their left index finger from its position on target 1 to target 2 (see Figure 1c). Participants were told not to start the second movement until the first had been completed, but to make this changeover as quickly as possible.

At the beginning of each trial, participants were presented with a warning tone, followed by a target tone after a 1500-2500 ms variable foreperiod. Participants were instructed to react and perform the movement(s) as quickly as possible in response to the onset of the target tone.

Each participant completed three blocks of trials, one for each aiming task (1T, 2T1L and 2T2L). At the start of each block, instructions were given about the task and the movement was demonstrated three times. Each participant was then given five practice trials prior to performing 25 test trials. The three blocks of trials were counterbalanced between participants.

\subsection{Statistical Methods}

Dependent measures consisted of reaction time (RT), movement time to the first target (MT1), pause time at target 1 (PT), and movement time from the first target to the second target (MT2). 


\section{MOVEMENT INTEGRATION IN PERSONS WITH DOWN SYNDROME}

RT was the interval from the presentation of the stimulus (auditory tone) to the release of the key press at the starting position. MT1 was measured from the release of the key press at the starting position to the pressing of the target 1 key. PT was the time between the pressing of target 1 and the release of the key press to perform the second movement. Finally, MT2 was the time from the release of the key press at target 1 to the pressing of target 2 .

Separate 3 Group (DS, UID, TD) x 3 Task (1T, 2T1L, 2T2L) ANOVAs with repeated measures on the second factor were performed on RT and MT1, whilst separate 3 Group (DS, UID, TD) x 2 Task (2T1L, 2T2L) ANOVAs with repeated measures on the second factor were performed on PT and MT2. As suggested by Stevens (2002), any significant main effects and interactions involving more than two means and where Epsilon was below .7 were further investigated using Bonferroni post hoc procedures $(p<.05$ with appropriate adjustments for multiple comparisons applied). In situations where Epsilon was above .7, main effects and interactions were further investigated using Tukey's (HSD) procedures $(p<$ $.05)$.

\section{Results}

Trials in which RT was less than $100 \mathrm{~ms}$ or greater than $800 \mathrm{~ms}$ and in which participants missed any of the required targets or initiated the second response element prior to completing the first were omitted from the analysis. This accounted for less than $5 \%$ of trials in any one participant.

\subsection{Reaction time}

Means and $S D$ s for all dependent measures are reported in Table 1.

Insert Table 1 about here 
MOVEMENT INTEGRATION IN PERSONS WITH DOWN SYNDROME

The analysis of RT revealed only a significant main effect for group $\left(F_{(2,21)}=10.96\right.$, $\left.p<.001, \eta_{p}{ }^{2}=.51\right)$ with RTs in the TD group (217 ms) being significantly shorter than those of the UID (347 ms; $i-j=-131.91, d=2.39, r=.77)$ and DS (349 ms; $i-j=-130.12, d=$ $1.78, r=.67$ ) groups (see Figure 2). There was no significant main effect for condition and no significant group $\times$ condition interaction.

Insert Figure 2 about here

\subsection{Movement time 1}

The movement time 1 analysis revealed a significant main effect for group $\left(F_{(2,21)}=\right.$ $\left.7.68, p<.05, \eta_{p}{ }^{2}=.42\right)$ and condition $\left(F_{(2,42)}=3.77, p<.05, \eta_{p}{ }^{2}=.15\right)$, but no interaction between these two factors. Specifically, MT1 was significantly longer in participants with DS (432 ms) compared to the UID (291 ms; $i-j=141.58, d=2.39, r=.77)$ and TD (239 ms; $i-j=193.66, d=1.19, r=.51)$ groups. The UID and TD groups were not significantly different from one another. Furthermore, the 1T condition had shorter MT1s (302 ms) than both the 2T1L (323 ms; $i-j=-23.02, d=0.20, r=.10)$ and 2T2L (337 ms; $i-j=-34.83, d$ $=0.32, r=.16$ ) conditions, which were not different from one another (see Figure 3).

\subsection{Pause time}

The analysis of PT revealed only a significant main effect for condition $\left(F_{(1,21)}=\right.$ 9.74, $p<0.05, \eta_{p}{ }^{2}=.31$ ) with pause times in the 2T2L condition (99 ms) being significantly less than the 2T1L condition $(221 \mathrm{~ms} ; i-j=-122.14, d=0.90, r=.41)$.

\subsection{Movement time 2}


MOVEMENT INTEGRATION IN PERSONS WITH DOWN SYNDROME

The analysis of MT2 revealed a significant main effect for group $\left(F_{(2,21)}=6.45, p<\right.$ $\left..05, \eta_{p}^{2}=.38\right)$ and condition $\left(F_{(1,21)}=5.81, p<.05, \eta_{p}^{2}=.22\right)$. Specifically, MTs were significantly longer in participants with DS (407 ms) compared to the UID (268 ms; $i-j=$ 138.41, $d=1.05, r=.47)$ and TD (237 ms; $i-j=169.83, d=1.41, r=.58)$ groups. As well, participants had longer MT2's under 2T2L (333 ms) compared to 2T1L (274 ms) conditions $(i-j=59.51, d=0.55, r=.27)$. The group $\times$ condition interaction was not significant.

\section{Discussion}

Research has revealed that individuals with DS are slower in initiating (Anson and Mawston, 2000; Davis, Sparrow, \& Ward, 1991; Henderson et al., 1991; Masumoto et al., 2012) and executing target directed movements (Elliott et al., 2006; Hodges et al., 1995) because they rely more on afferent information to correct movement trajectories (Elliott et al., 2006, 2010; Hodges et al., 1995). These patterns of results have often been attributed to both central processes (Frith \& Frith, 1974) and peripheral anatomical characteristics (Henderson et al, 1991; Morris et al., 1982) associated with DS. However, much of the goal-directed aiming research investigating DS has been conducted on single arm single sequence movements. As such, the present study investigated the planning and execution of multiple target sequential aiming movements to determine whether participants with DS use similar control strategies to the TD population. Specifically, we compared two target movements performed with a single arm to those in which there was a switch between arms at the first target in order to investigate whether perceptual-motor deficits in the DS population are due to central or peripheral issues.

Consistent with past research conducted on TD adults (Adam et al., 2000; Helsen et al., 2001; Khan et al., 2010; Lavrysen et al., 2003), we found that increasing the number of response segments in a manual aiming movement produced an increase in the time taken to execute the first segment in a sequence. This finding was observed regardless of whether the 
MOVEMENT INTEGRATION IN PERSONS WITH DOWN SYNDROME

participants were intellectually challenged (DS and UID) or non-intellectually challenged (TD). Furthermore, this OTA was present when sequential movements were performed with either one or two arms. Hence, similar to TD and UID participants, the existence of the OTA for individuals with DS indicates that movements within a sequence are not prepared and executed independently.

Past literature has offered two explanations for the OTA; the movement integration hypothesis (MIH; Adam et al., 2001) and the movement constraint hypothesis (MCH; Sidaway, Sekiya \& Fairweather, 1995). According to the MIH, the first movement is carefully monitored so that the parameters of the second movement can be implemented at a time that enables optimal integration between the two movements. Because the implementation of the second segment is performed online concurrent with the execution of the first, the increased cognitive control associated with this overlap leads to interference and hence the lengthening of MT to the first target. The MCH on the other hand, proposes that the OTA occurs because movements to the first target in two element responses must be performed in a more constrained manner in order to ensure the accuracy requirements of the already planned subsequent movement are met. Research has revealed that both the movement integration and movement constraint hypotheses play a role in the control of single arm sequential aiming movements (Khan et al., 2011). However, because the starting point of the second movement was fixed in the dual arm condition, it is unlikely that the $\mathrm{MCH}$ can explain the emergence of the OTA in the dual arm condition of the present experiment. Under dual arm conditions the endpoint variability of the first movement is not relevant to the production of the second movement when there is a switch in arms between the two movements. Hence there is no requirement to constrain the variability of the first movement in the two-target dual arm condition. Therefore, the emergence of the OTA in the 
MOVEMENT INTEGRATION IN PERSONS WITH DOWN SYNDROME

dual arm condition of the present investigation lends support for the movement integration explanation of the OTA rather than that of the movement constraint hypothesis.

Based on research that has involved single arm aiming movements, Adam et al. (2000) suggested that the loci of interference underlying movement integration could occur at either a central level (i.e., the retrieval or initiation of motor programs) or peripheral level (i.e., interference/alterations in muscle recruitment patterns associated with the first movement when a second movement is required). Consistent with Khan et al. (2010), the results of the present study revealed that the OTA emerged for single arm aiming movements and when there was a switch in arms at the first target. Furthermore, for both TD and DS groups, the magnitude of the OTA was similar for single and dual arm conditions. Since the presence and magnitude of the OTA was not effector dependent, these findings extend the results of Khan et al. to individuals with DS suggesting a central rather than a peripheral locus of interference.

Whilst the results of the current investigation revealed a significant OTA, there was no significant difference in RT between responses that required only the single movement (1T) or the more complex multiple movements $(2 \mathrm{~T} 1 \mathrm{~L}$ or $2 \mathrm{~T} 2 \mathrm{~L})$. It is possible that all movement programming was completed during the foreperiod (i.e., the time interval between the warning signal and stimulus of each trial) eliminating any increase in RT as a result of increasing the number of movements within a response. However, previous research has revealed increases in simple reaction time (SRT) with increases in the number of response movements (Khan et al., 2006; Klapp, 1995, 2003). An alternative explanation is that participants were programming the movement parameters of the second movement online during the execution of the first (see Chamberlin \& Magill, 1989; Khan et al., 2006). Under these circumstances, the complex two-movement sequences would not have been programmed in their entirety during the reaction time interval. Rather, participants would 


\section{MOVEMENT INTEGRATION IN PERSONS WITH DOWN SYNDROME}

have adopted a strategy of programming the first segment of the response during reaction time and then completed the programming of the later segment during the execution of the first. The additional programming requirements associated with preparing the second movement during the execution of the first would have required increased cognitive processing and resulted in an increase in the time required to perform the first movement. It is important to note that regardless of whether the OTA occurred due to the processes involved in the MIH (Adam et al., 2000) or the online programming hypothesis (Chamberlin \& Magill, 1989; Khan et al., 2006) both hypotheses propose central processes as being responsible for the increase in movement time.

Although non-significant, there was a tendency for the OTA to be greater in the dual arm condition than the single arm condition for individuals with DS (see Figure 3 ). ${ }^{1}$ It is possible that the increase in movement time required to integrate movement segments across arms was due to the involvement of the non-dominant left hand in the dual arm responses. Research has revealed that finger-tapping times are slower in the left hand compared to the right hand of individuals with DS suggesting that the motor programs required to initiate movement of the left arm require greater cognitive processes than that of the right arm (Elliott, 1985; Elliott \& Chua, 1996). Hence, the increase in the OTA for the dual arm responses suggests that participants with DS needed to apply greater cognitive resources than their TD and UID peers when attempting to integrate movements when there was a switch to the non-dominant hand.

Alternatively, the larger OTA under dual-arm conditions for participants with DS could reflect the need for interhemispheric integration when both the right and left arm are involved in the aiming sequence. This suggestion is consistent with the finding that anomalies in the development of the corpus callosum in persons with DS negatively impacts communication between the left and right cerebral hemispheres (Wang, Doherty, Hesselink, 


\section{MOVEMENT INTEGRATION IN PERSONS WITH DOWN SYNDROME}

\& Bellugi, 1992; see also Heath, Grierson, Binsted \&, Elliott, 2007). This type of communication is important for the precise coordination of right and left-sided limb movements.

\subsection{Conclusion}

For DS, UID, and TD individuals, movement time to the first target was longer in two-target sequential movements compared to single-target movements. The presence of the OTA implies that similar to the TD population, individuals with DS do not prepare and control segments of multiple target aiming sequences independently. Furthermore, the OTA emerged regardless of whether the entire movement sequence was performed with a single arm or when the arm was switched at the first target. This implies that the processes underlying the OTA are not arm specific. Thus, similar to TD individuals (Khan et al., 2010), it appears that for individuals with DS, central rather than peripheral processes underlie the cause of the OTA. These results suggest that any central deficits associated with DS do not prevent the adoption of movement strategies designed to increase the integration of elements within responses and that these integration strategies likely involve anticipatory behaviour (i.e., implementing the second movement in a sequence at an appropriate time during the execution of the first) in order to maximise the smooth transition between movements.

Although more research on movement coordination is needed to extend the current findings, our results suggest that within and between-limb response sequencing in DS is not constrained by the anatomical/physiological phenotype associated with the syndrome. For a clinical point of view, this means that skill training and rehabilitation protocols similar to those used with other intellectually challenged persons should also be effective for persons with DS (Hoover \& Wade, 1985). With that said, one should keep in mind that most of the work on perceptual-motor speed in persons with DS has been conducted using single segment 


\section{MOVEMENT INTEGRATION IN PERSONS WITH DOWN SYNDROME}

goal-directed movement. Practitioners should be mindful of this when designing learning interventions for complex multiple movement actions. This is especially important given that the findings of the current investigation revealed that adults with DS apply similar movement planning and control strategies as TD persons when controlling actions with multiple movements. In future research, multi-segment movements might be studied in the context of practical tasks important of the development of self-help, recreational and work related skills (e.g., food preparation, key board and writing skills, equipment operation, grooming and sport skills). 
Acknowledgements: This research was partially funded by the European Social Fund through the Knowledge Economy Skills Studentship (KESS) scheme via the European Union's Convergence programme administered by the Welsh Government. The authors would like to thank the company partner of the KESS scheme, Mr Wayne Crocker (Director of Mencap Cymru). 
MOVEMENT INTEGRATION IN PERSONS WITH DOWN SYNDROME

\section{References}

Adam, J. J. Nieuwenstein, J. Huys, R. Paas, F., Kingma, H., Willems, P, \& Werry, M. (2000). Control of rapid aimed hand movements: The one-target advantage. Journal of Experimental Psychology: Human Perception and Performance, 26, 295-312.

Almedia, G., Corcos, D. M., \& Hasan, Z. (2000). Horizontal-plane arm movements with direction reversals performed by normal individuals and individuals with Down syndrome. Journal of Neurophysiology, 84, 1949-1960.

Anson, J. G. (1989). Down syndrome: Neuromotor programming and fractionated reaction time. In M. L. Latash (Ed.), Motor Control in Down Syndrome (pp. 234-251). Chicago, IL.

Anson, J. G., \& Mawston, G.M. (2000). Patterns of muscle activation in simple reactiontime tasks. In D.J. Weeks, R. Chua, \& D. Elliott (Eds), Perceptual-Motor Behavior in Down Syndrome (pp. 3-24). Champaign, IL: Human Kinetics.

Anwar, F., \& Hermelin, B. (1979). Kinesthetic movement aftereffects in children with Down's syndrome. Journal of Mental Deficiency, 23,287-297.

Arisi, E., Forti, S., Amadeo, C., Fagnani, E., Filipponi, E., Iacona, E., et al. (2012). Auditory late potentials in normal-hearing adult subjects with Down's syndrome. Otology \& Neurotology, 33(7), 1113-1117.

Arscott, K., Dagnan, D., \& Kroese, B. S. (1998). Consent to psychological research by people with an intellectual disability. Journal of Applied Research in Intellectual Disabilities, 11(1), 77-83.

Carvalho, R. L., \& Vasconcelos, D. A. (2011). Motor Behavior in Down Syndrome: Atypical Sensoriomotor Control. Prenatal Diagnosis and Screening for Down syndrome. Rijeka: InTech, 33-43. 


\section{MOVEMENT INTEGRATION IN PERSONS WITH DOWN SYNDROME}

Chamberlin, C. J., \& Magill, R. A. (1989). Preparation and control of rapid, multisegmented responses in simple and choice environments. Research Quarterly for Exercise and Sport, 60, 256-267.

Davis, W. E., Sparrow, W. A., and Ward, T. (1991). Fractionated reaction times and movement times of Down syndrome and other adults with mental retardation. Adapted Physical Activity Quarterly, 8, 221-233.

Dunn, L. M. \& Dunn, L. M. (1997). Peabody Picture Vocabulary Scale - Third Edition (PPVT-III). Circle Pines, Minnesota: American Guidance Service.

Elliott, D. (1985). Manual asymmetries in the performance of sequential movement by adolescents and adults with Down syndrome. American Journal of Mental Deficiency, 90, 90-97.

Elliott, D. \& Chua, R. (1996). Manual asymmetries in goal-directed movement. In D. Elliott and E. A. Roy (Eds), Manual asymmetries in motor performance (pp.143-158). Boca Raton, FL: CRC Press.

Elliott D., Hansen S., Grierson L. E., Lyons J., Bennett S. J., Hayes S. J. (2010). Goal directed aiming: Two components but multiple processes. Psychology Bulletin, 136, 1023-1044.

Elliott, D., Welsh, T.N., Lyons, J., Hansen, S., \& Wu, M. (2006). The visual regulation of goal-directed reaching movements in adults with Williams syndrome, Down syndrome and other developmental delays. Motor Control, 10, 34-54.

Frith, U., \& Frith, C. D. (1974). Specific motor disabilities in Down's Syndrome. Journal of Child Psychology and Psychiatry, 15, 293-301.

Heath, M., Grierson, L., Binsted, G., \& Elliott, D. (2007). Interhemispheric transmission time in persons with Down syndrome. Journal of Intellectual Disability Research, $51,972-981$. 


\section{MOVEMENT INTEGRATION IN PERSONS WITH DOWN SYNDROME}

Helsen, W. F., Adam, J. J., Elliott, D., \& Buekers, M. J. (2001). The one-target advantage: A test of the movement integration hypothesis. Human Movement Science, 20, 643674.

Henderson, S. E., Illingworth, S. M., \& Allen, J. (1991). Prolongation of simple manual and vocal reaction times in Down syndrome. Adapted Physical Activity Quarterly, 8, 234241.

Henderson, S. E., Morris, J., \& Frith, U. (1981). The motor deficit in Down's syndrome children: A problem of timing? Journal of Child Psychology and Psychiatry, 22(3), 233-245.

Henry, F. M., \& Rogers, D. E. (1960). Increased response latency and a "memory drum" theory of neuromotor reaction. Research Quarterly, 31, 448-458.

Hodges, N. J., Cunningham, S. J., Lyons, J., Kerr, T. L., \& Elliott, D. (1995). Visual feedback processing and goal-directed movement in adults with Down syndrome. Adapted Physical Activity Quarterly, 12, 176-186.

Hoover, J.H., \& Wade, M.G. (1985). Motor learning theory and mentally retarded individuals: A historical review. Adapted Physical Activity Quarterly, 2, 228-252.

Inui, N. (2007). Simple reaction times and timing of unimanual and bimanual serial actions in adolescents with mental retardation, autism and Down syndrome. In E. B. Heinz (Ed.), Mental Retardation, Research Advances (pp. 109-134). New York: Nova Science Publishers.

Kerr, R., \& Blais, C. (1987). Down syndrome and extended practice of a complex motor task. American journal of mental deficiency, 91(6), 591.

Khan, M. A., Franks, I. M., Elliott, D., Lawrence, G. P., Chua, R., Bernier, P. M., et al. (2006). Inferring online and offline processing of visual feedback in target-directed movements from kinematic data. Neuroscience and Biobehavioral Reviews, 30(8), 1106-1121. 
MOVEMENT INTEGRATION IN PERSONS WITH DOWN SYNDROME

Khan, M. A., Lawrence, G. P., Buckolz, E., \& Franks, I. M. (2006). Programming strategies for rapid aiming movements under simple and choice reaction time conditions. Quarterly Journal of Experimental Psychology, 59 (3): 524-542.

Khan, M. A., Mottram, T. M., Adam, J. J., \& Buckolz, E. (2010). Sequential aiming with two limbs and the one-target advantage. Journal of Motor Behavior, 42 (5), 325-330.

Khan, M. A., Sarteep, S., Mottram, T. M., Lawrence, G. P., \& Adam, J. J. (2011). The dual role of vision in sequential aiming movements. Acta Psychologica, 136 (3), 425-431.

Klapp, S. T. (1995). Motor response programming during simple and choice reaction time: The role of practice. Journal of Experimental Psychology: Human Perception and Performance, 21, 1015-1027.

Klapp, S. T. (2003). Reaction time analysis of two types of motor preparation for speech articulation: Action as a sequence of chunks. Journal of Motor Behavior, 35, 135150.

Klapp, S. T., Wyatt, E. P. \& Lingo, W. M. (1974). Response programming in simple and choice reactions. Journal of Motor Behavior, 6, 263-271.

Lam, M.Y., Hodges, N. J., Virji-Babul, N., Latash, M. L. (2009). Evidence for slowing as a function of index of difficulty in young adults with Down syndrome. American Journal on Intellectual and Developmental Disabilities. 114, 411-426.

Latash, M. L. (2007). Learning motor synergies by persons with Down syndrome. Journal of Intellectual Disability Research, 51, 962-971.

Lavrysen, A., Helsen, W. F., Elliott, D., \& Adam, J. J. (2002). The one-target advantage: Advanced preparation or online processing? Motor Control, 6, 230-245.

Lavrysen, A., Helsen, W. F., Tremblay, L., Elliott, D., Adam, J. J., Feys, P., et al. (2003). The control of sequential aiming movements: The influence of practice and manual asymmetries on the one-target advantage. Cortex, 39, 307-325. 


\section{MOVEMENT INTEGRATION IN PERSONS WITH DOWN SYNDROME}

Masumoto, J., Abe, T., \& Inui, N. (2012). Adolescents with Down syndrome exhibit greater force and delay in onset of tapping movements. Perceptual and Motor Skills, 114(3), 826-836.

Morris, A. F., Vaughan, S. E. \& Vaccaro, P. (1982). Measurement of neuromuscular tone and strength in Down's syndrome children. Journal of Mental Deficiency Research, 26, 41-46.

Savelberg, H. H. C. M., Adam, J. J., Verhaegh, R. H. J., \& Helsen, W. F. (2002). Electromyographic pattern in fast goal-directed arm movements. Journal of Human Movement Studies, 43, 121-133.

Schmidt, R. A., Zelaznik, H., Hawkins, B., Frank, J. S., \& Quinn, J. T. (1979). MotorOutput Variability - Theory for the Accuracy of Rapid Motor Acts. Psychological Review, 86(5), 415-451.

Sidaway, B., Sekiya, H., \& Fairweather, M. (1995). Movement variability as a function of accuracy demand in programmed serial aiming responses. Journal of Motor Behavior, 27, 67-76.

Simon, D. A., Elliott, D. \& Anson, J. G. (2003). Perceptual-motor behaviour in children with Down syndrome. In G. Savelbergh, K.Davids, J. van der Kamp, and S. Bennett (Eds), Development of movement coordination in children: Applications in the fields of ergonomics, health sciences and sport (pp.133-155). London, UK: Routledge.

Sternberg, S., Monsell, S., Knoll, R. L., \& Wright, C. E. (1978). The latency and duration of rapid movement sequences: Comparisons of speech and typewriting. In G. E. Stelmach (Ed.), Information processing in motor control and learning (pp 77-112). New York: Academic Press.

Stevens, J. (2002). Applied multivariate statistics for the social sciences. Lawrence Erlbaum Associates: New Jersey. 


\section{MOVEMENT INTEGRATION IN PERSONS WITH DOWN SYNDROME}

Vidal, F., Bonnet, M. L., \& Macar, F. (1991). Programming response duration in a precueing reaction time paradigm. Journal of Motor Behavior, 23, 226-234.

Wang, P. P., Doherty, S., Hesselink, J. R., \& Bellugi, U. (1992). Callosal morphology concurs with neurobehavioral and neuropathological findings in two neurodevelopmental disorders. Archives of Neurology, 49, 407-411. 


\section{Footnotes}

1. Separate paired samples $t$-tests performed between the single-and dual arm MT1 group data revealed that the OTA of the DS group was significantly greater in the two arm (61 ms) compared to single arm $(9 \mathrm{~ms})$ condition $(t(7)=-2.49, p<.05)$. Both the UID and TD groups did not reveal significant differences between the single-and dual arms conditions $(p>.05)$. 
Table 1. Means and $S D s(\mathrm{~ms})$ for reaction time (RT), movement time to first target (MT1), pause time (PT), and movement time to the second target (MT2) for group (Down syndrome, DS; higher functioning undifferentiated intellectual disability, UID; and typically developing, TD) and condition (one-target, 1T; two-target, one-limb, 2T1L; and two-target, two-limb, 2T2L).

\begin{tabular}{|c|c|c|c|c|c|c|c|c|c|}
\hline & \multicolumn{3}{|c|}{ DS } & \multicolumn{3}{|c|}{ UID } & \multicolumn{3}{|c|}{ TD } \\
\hline & $1 T$ & 2T1L & $2 \mathrm{~T} 2 \mathrm{~L}$ & 1T & 2T1L & $2 \mathrm{~T} 2 \mathrm{~L}$ & 1T & 2T1L & $2 \mathrm{~T} 2 \mathrm{~L}$ \\
\hline \multirow[t]{2}{*}{ RT } & 348 & 346 & 352 & 331 & 337 & 374 & 205 & 224 & 223 \\
\hline & 52 & 77 & 80 & 102 & 75 & 113 & 33 & 35 & 38 \\
\hline \multirow[t]{2}{*}{ MT1 } & 409 & 418 & 470 & 276 & 300 & 297 & 221 & 252 & 243 \\
\hline & 112 & 80 & 112 & 145 & 140 & 112 & 65 & 81 & 90 \\
\hline \multirow[t]{2}{*}{ PT } & --- & 256 & 146 & --- & 304 & 121 & --- & 103 & 30 \\
\hline & & 69 & 113 & & 97 & 45 & & 23 & 41 \\
\hline \multirow[t]{2}{*}{ MT2 } & --- & 347 & 466 & --- & 255 & 281 & --- & 220 & 253 \\
\hline & & 111 & 204 & & 117 & 80 & & 63 & 68 \\
\hline
\end{tabular}


A)

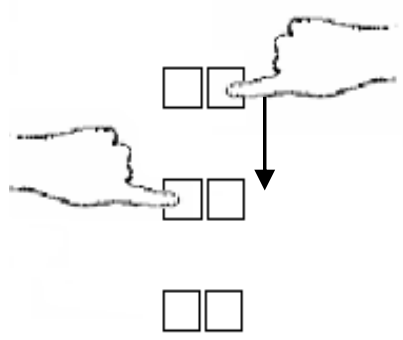

B)

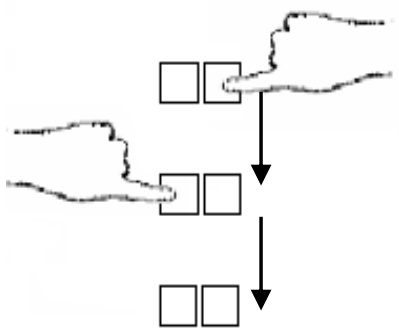

C)

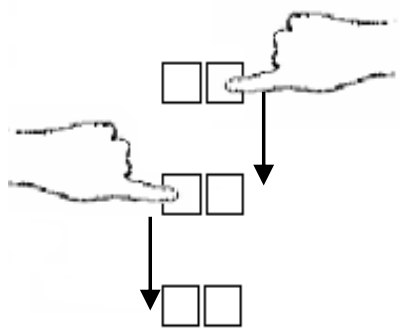

Figure 1. Starting position of fingers for the 3 conditions used in the study. A) Single target (1T); B) Two-target, single limb (2T1L); C) Two-target, two limbs (2T2L). 


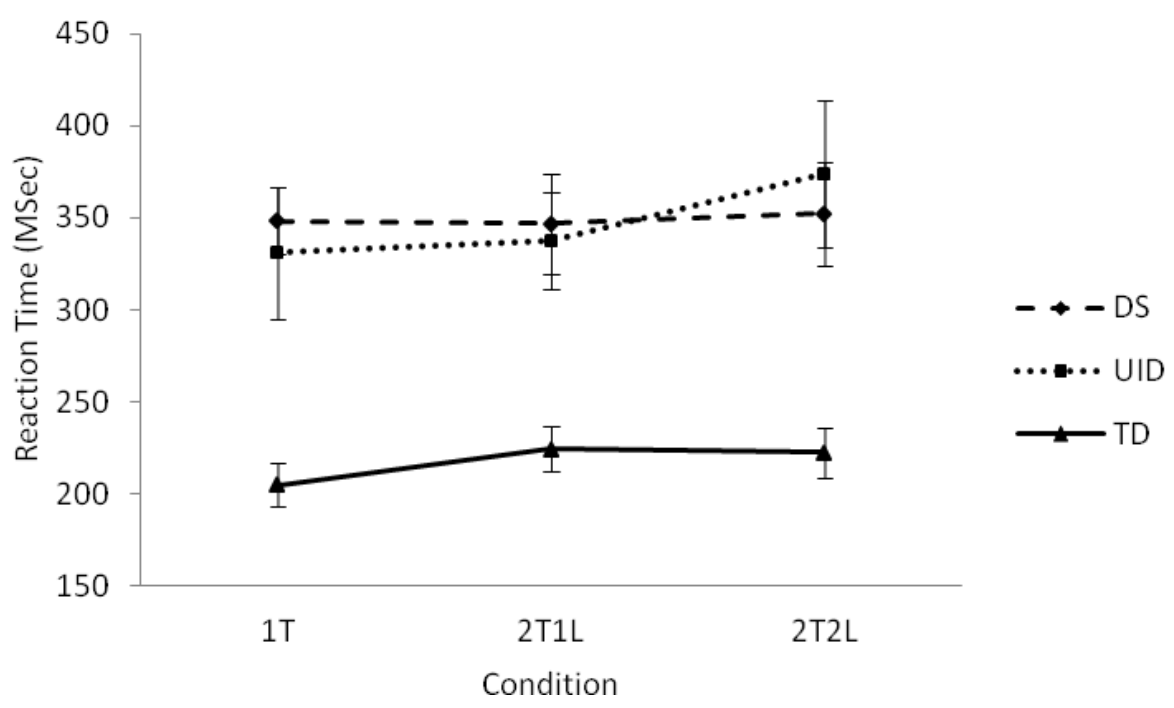

Figure 2. Reaction time as a function of group (DS = Down syndrome; UID = higher functioning undifferentiated intellectual disability; and TD = typically developing) and condition $(1 \mathrm{~T}=$ one-target; $2 \mathrm{~T} 1 \mathrm{~L}=$ two-target, one limb; and $2 \mathrm{~T} 2 \mathrm{~L}=$ two-target, two limb $)$. 


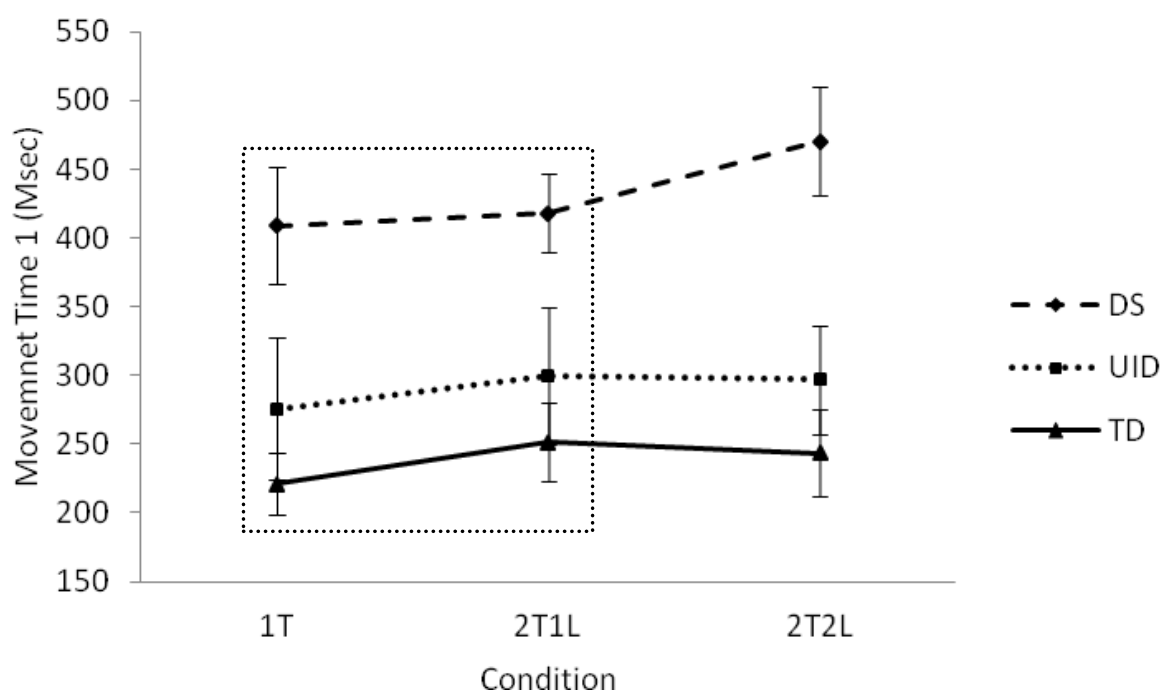

Figure 3. Movement time to the first target as a function of group (DS = Down syndrome; UID = higher functioning undifferentiated intellectual disability; and TD = typically developing $)$ and condition $(1 \mathrm{~T}=$ one-target; $2 \mathrm{~T} 1 \mathrm{~L}=$ two-target, one limb; and 2T2 $\mathrm{L}=$ twotarget, two limb). The box encapsulating the data from all groups within the $1 \mathrm{~T}$ and $2 \mathrm{~T} 1 \mathrm{~L}$ conditions highlights the significant OTA observations. 
MOVEMENT INTEGRATION IN PERSONS WITH DOWN SYNDROME

Source of Funding

This research was conducted through a Knowledge Economy Skills Scholarship scheme (KESS) and part-funded by the European Social Fund (ESF) through the European Union's Convergence programme administered by the Welsh Government. 